\title{
Snow Cover Extent and Duration in MODIS Time Series: a Comparison with In-Situ Measurements (Provincia Verbano Cusio Ossola, NW Italy)
}

\author{
Danilo Godone ${ }^{\#}$ Gianluca Filippa ${ }^{\#}$, Silvia Terzago ${ }^{+}$, Enrico Rivella ${ }^{\circ}$, Alessio Salandin ${ }^{\circ}$, \\ Secondo Barbero ${ }^{\circ}$, Gabriele Garnero ${ }^{\#}$, Michele Freppaz ${ }^{*}$ \\ ${ }^{*}$ DEIAFA, Faculty of Agriculture, University of Turin \\ NATRISK - Research Centre on Natural Risks in Mountain and Hilly Environments \\ ${ }^{+}$Earth Sciences Department, University of Turin \\ ${ }^{\circ}$ Regional Environmental Protection Agency \\ danilo.godone@unito.it \\ gianluca.filippa@unito.it
}

\begin{abstract}
An automated approach is presented, with the purpose of computing snow cover duration from satellite imagery and to validate them with in-situ measured data. In the present study the employed MODIS dataset has a spatial domain covering the entire study area, while its temporal domain covers the last ten years, i.e. 2000 - 2010. Snow depth records from sensors integrated in automated nivo-meteorological stations were used to provide field measurements for comparison with the MODIS data. The meteorological network records snow and climate variables such as snow depth, air temperature, wind speed, and soil temperature. Snow depth is measured from above with an ultrasonic snow depth sensor (mounted on a mast $6 \mathrm{~m}$ above ground). The two independent automated procedures to derive snow patterns and particularly to define the end of snowmelt have shown a fairly good agreement. Moreover, the study has shown that a strong influence on the relationship between MODIS and snow-sensor derived snow melts may be due to the elevation, with higher sites showing longer lasting snowpacks under the snow sensor than over the $\mathbf{5 0 0}$ m-side grid.
\end{abstract}

Keywords-GIS; Nivo-meteorological Station; Remote Sensing; Snowmelt; Visual Basic

\section{INTRODUCTION}

Snow cover plays an important role within the global heat budget [2]. Its variation in space and time is the result of variability in earth's climate system [1], as well as being one of the important controlling parameters for many hydrological, physical, chemical and biological processes [13], such as the vegetation phenology.

The high reflectivity of snow, combined with the high surface coverage (during winter in Northern Hemisphere snow can cover more than $40 \%$ of the total area), make the snow a key component of planet's radiation budget.

Satellite remote sensing allows exploiting snow physical characteristics in order to measure its cover (and its duration), mainly because of its high albedo that leads to a high contrast compared to other surfaces (except clouds) [3]. The albedo is the amount of reflected radiation from the solar radiation and snow albedo can take very high values, between $80 \%$ and $40 \%$ respectively in case of fresh snow or processed and/or dirty [1].

Since '60, when snow was observed for the first time in a TIROS-1 (Television and Infrared Observation Satellite) scene [16], satellites have been employed in snow observation. Nowadays, the freely available Moderate Resolution Imaging Spectroradiometer (MODIS) snow cover products, with $500 \mathrm{~m}$ spatial and daily temporal resolution, can provide a basis for regional snow-cover mapping, monitoring and hydrological modelling [17]. In particular it may indicate the melt-out date (MOD), a key parameter for example for vegetation growth. The ground validation of remote sensing measurements with coarse resolution implies considerable difficulties, but the analysis of data from the nivo-meteorological stations may represent a useful support.

\section{MATERIAL AND METHODS}

\section{A. Study Area}

The study area (Fig. 1) corresponds to the Verbano Cusio Ossola Province (Piemonte, Italy) covering a $2.255 \mathrm{~km}^{2}$ surface $\left(46^{\circ} 29^{\prime} \mathrm{N} ; 7^{\circ} 52^{\prime} \mathrm{E}-4^{\circ} 46^{\prime} \mathrm{N} ; 8^{\circ} 44^{\prime} \mathrm{E}\right)$. The elevation ranges from $193 \mathrm{~m}$ ASL to $4634 \mathrm{~m}$ ASL (Monte Rosa massif).

The area is characterized by a temperate climate, influenced by the Alpine environment. The Province is one of the rainiest areas in Italy (2350 mm/year). .

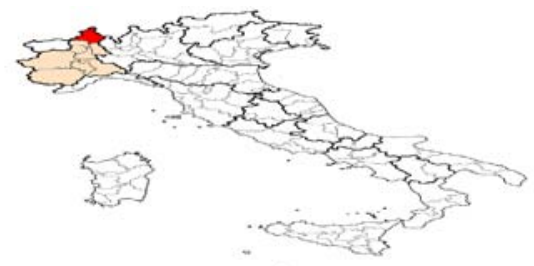

Fig. 1 Study area (highlighted in red) in Piemonte Region (light red), Italy Public domain map. 


\section{B. MODIS Data}

MODIS (Moderate Resolution Imaging Spectroradiometer) is a sensor, mounted on TERRA and AQUA satellites belonging to EOS (Earth Observing System). It is characterized by 36 spectral bands ranging from $0.4 \mu \mathrm{m}$ to $14.4 \mu \mathrm{m}$. MODIS observation are employed to generate daily snow cover maps characterized by a 500m resolution [8], [9], [11].

In the present study the employed dataset has a spatial domain covering the entire study area, while its temporal domain covers the last ten years, i.e. 2000 - 2010, subdivided in 506 scenes in ASCII exchange format (.ASC.

In order to assess the snow cover fluctuations in the last decade, the data had to be recoded in order to obtain a binary classification, i.e. Snow/No Snow. A third code, No Data, has been kept with the purpose of spotting scenes characterized by low or no information.

To assign elevation values to MODIS data a Digital Elevation Model has been considered (Regione Piemonte Map Service). The model supplied in ESRI GRID format at $50 \mathrm{~m}$ cell size has been, firstly, resampled at $500 \mathrm{~m}$ with the aim of adjusting its resolution to that of MODIS. Elevation.

Then, its cells are used as sampling points with the purpose of filling in tables reporting elevation ranges and snow cover codes. The GIS tool, in fact, employs digital elevation model cells location to sample, in a multitemporal approach, MODIS rasters.

\section{Visual Basic Programming}

In order to process the whole dataset in a unique processing, a programming language has been employed. Thanks to authors' previous experiences with geographic data processing, Visual Basic 6.0 (VB) has been selected [8]. In its programming environment, processing software has been programmed, thus joining GIS based tools with VB capabilities in batch processing and data management.

The employed release, named "Modis VBA 2.0" is an improvement of the first one, equipped with user interfaces and a revised code (Fig. 2).

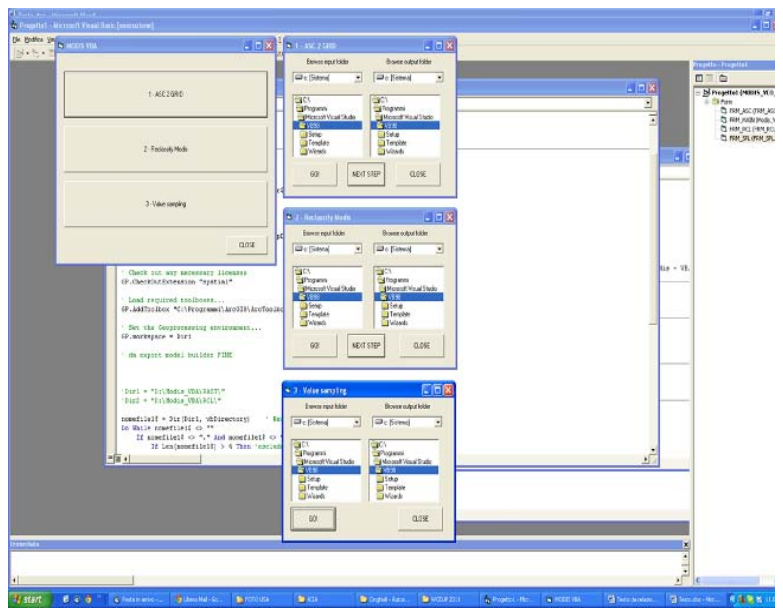

Fig. 2 “Modis VBA 2.0” interface
The software tools process is subdivided in three steps:

1. Conversion of input data in ESRI GRID format;

2. Raster values reclassification (TABLE I);

TABLE I

MODIS CELL VALUES WITH RELATIVE MEANING AND RECLASSIFICATION CODES

\begin{tabular}{|l|l|l|}
\hline Integer Value & Meaning & Code \\
\hline 255 & Fill Data--no data expected for pixel & 3 \\
\hline 254 & Saturated MODIS sensor detector & 3 \\
\hline 200 & Snow & 1 \\
\hline 100 & Snow-Covered Lake Ice & 1 \\
\hline 50 & Cloud Obscured & 3 \\
\hline 39 & Ocean & 2 \\
\hline 37 & Inland Water & 2 \\
\hline 25 & Land--no snow detected & 2 \\
\hline 11 & Darkness, terminator or polar & 3 \\
\hline 1 & No Decision & 3 \\
\hline 0 & Sensor Data Missing & 3 \\
\hline
\end{tabular}

3. Values sampling according to Digital Elevation Model cells.

GIS tools codes have been taken from ESRI ArcMap help files [4] in Phyton and adapted to Visual Basic syntax.

Every step processes the whole dataset and allows the user to continue to the next one, until the end of the procedure or to stop and exit, with the aim of checking data in GIS software.

\section{Snow Sensor Data}

Snow depth records, from sensors integrated in automated nivo-meteorological stations, were used to provide field measurements for comparison with the MODIS data [6]. The meteorological network considered in this study is run by the Piemonte Regional Environmental Agency and records snow and climate variables at 30-minute intervals. Snow depth is measured from above with an ultrasonic snow depth sensor, mounted on a mast $6 \mathrm{~m}$ above ground (Fig. 4).

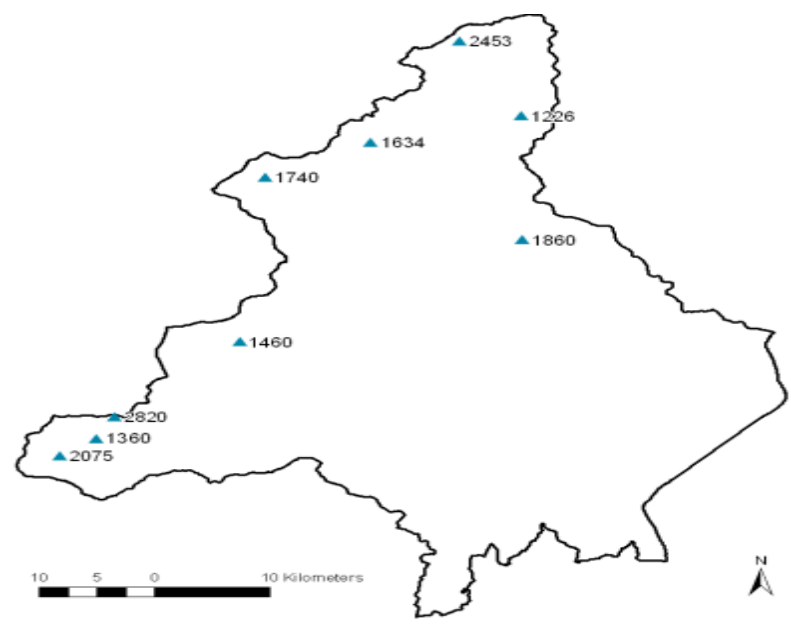

Fig. 3 Map of nivo-meteorological stations labelled with their elevation (m ASL) 


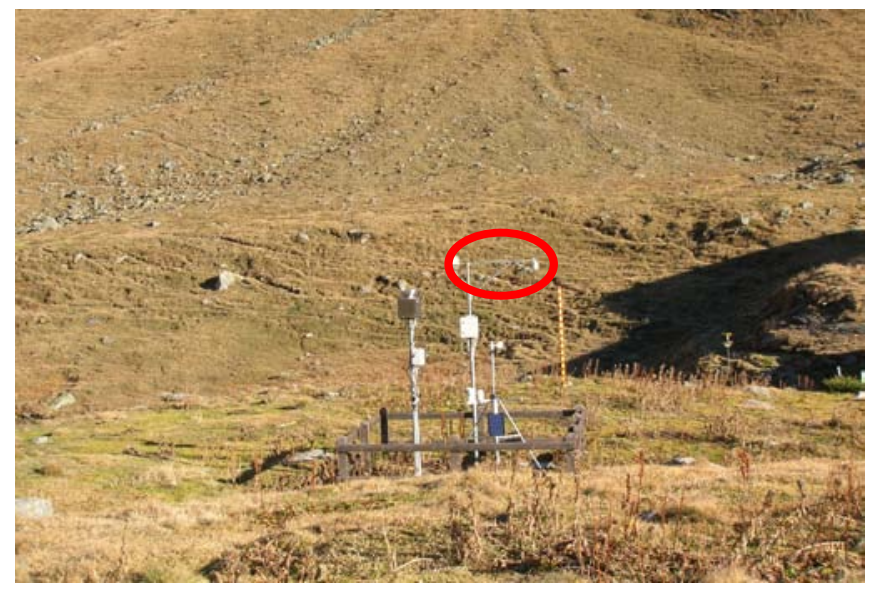

Fig. 4 Automatic nivo-meteorological station, the red circle denotes the snow sensor

The 9 meteorological stations that were equipped with snow sensors range in elevation from 1820 to $2820 \mathrm{~m}$ ASL (Fig. 3). The analysis, which covers a time frame from 2000 to 2010, resulted therefore in 96 yearly datasets (for one station, the measurement period started 3 years later, in 2003).

The half-hourly records form the snow sensors were averaged on a daily basis, and the median values were used for further analysis.

From an automated procedure implemented on R software [15], the melt-out date (MOD) has been derived for each station for each year.

When MOD could not be uniquely defined due to successive snow depositions, the snow melt has been set in the first moment when site were snow free, except those cases when the successive snowfall lead to a snow accumulation lasting longer than 7 days (i.e. the time-span between two successive MODIS images). In such case, MOD was set to the moment the site became snow free after the latest snowfall.

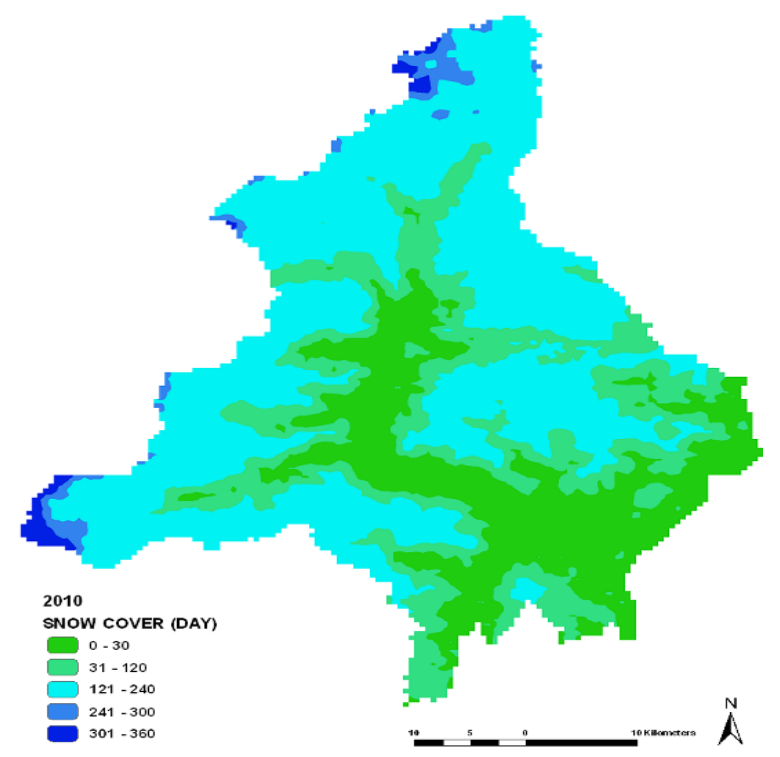

Fig. 52010 snow cover map of the study area.

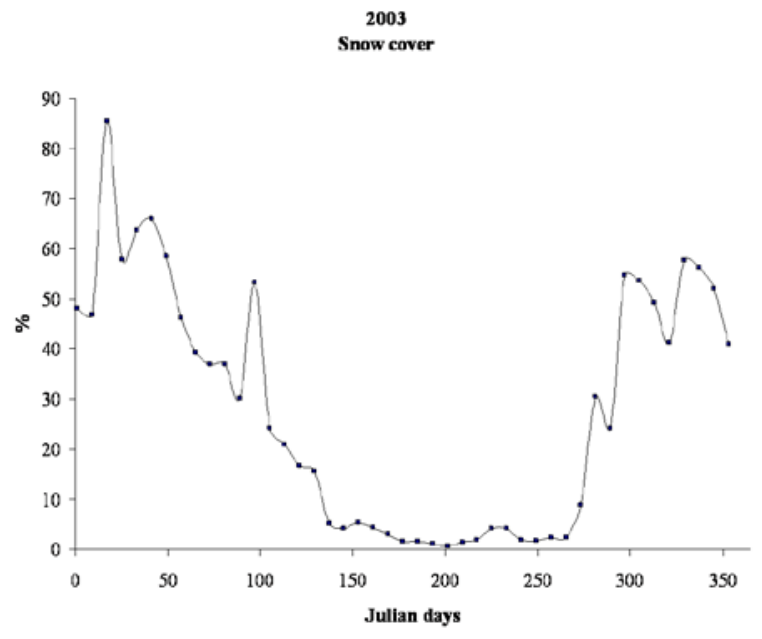

Fig. 6 Graph showing snow cover distribution in time (year 2003)

Eight cases over the 96 in total (i.e. less than $10 \%$ of the data) were excluded because they clearly showed a failure in snow sensor operation in the snow melt period.

\section{E. Data Comparison}

The comparison between in-situ measurements and MODIS data was performed by comparing one single variable: the MOD. For the purpose of evaluating the agreement between MODIS-derived and snow-sensor-derived snow melt dates, MOD from MODIS data has been extracted from the output of data processing described above within the $500 \mathrm{~m} \mathrm{x}$ $500 \mathrm{~m}$ grid where a given snow sensor was located. The process has been performed by employing stations locations, instead of Digital Elevation Model cells, as sampling points in the last step of "Modis VBA 2.0" software.

\section{RESULTS AND DISCUSSIONS}

\section{A. MODIS Data}

The entire dataset has been processed automatically by the "Modis VBA 2.0" software. Each single raster has been converted in ESRI GRID format, reclassified according to the table 1 each cell has also been sampled from digital elevation model cells location. The final outputs are 10 tables, for each year of MODIS observation, containing the previously listed data and their cartographical representation (Fig. 5).

Every table has, firstly, allowed plotting graphically the snow cover trend for each year as a percentage of covered surface (Fig. 6).

Then tables have been compared with weather stations data.

\section{B. Snow Sensor Data and Comparison}

Snow melt dates as measured by snow sensors for all 11 years and all sites ranged from DOY 72 to DOY 214, with a median of 131; reflecting a combined effect of the inter-year variability in the total snowfall and the elevation range of the stations in determining the snowmelt date.

The comparison of MOD, as determined by the two methods lead to a range of results from fairly good agreement, when MOD from snow sensors felt within the weekly time- 
span of the MODIS-derived MOD, to bad ones, when there was a discrepancy as high as 30 days between the two estimates (Fig. 7).

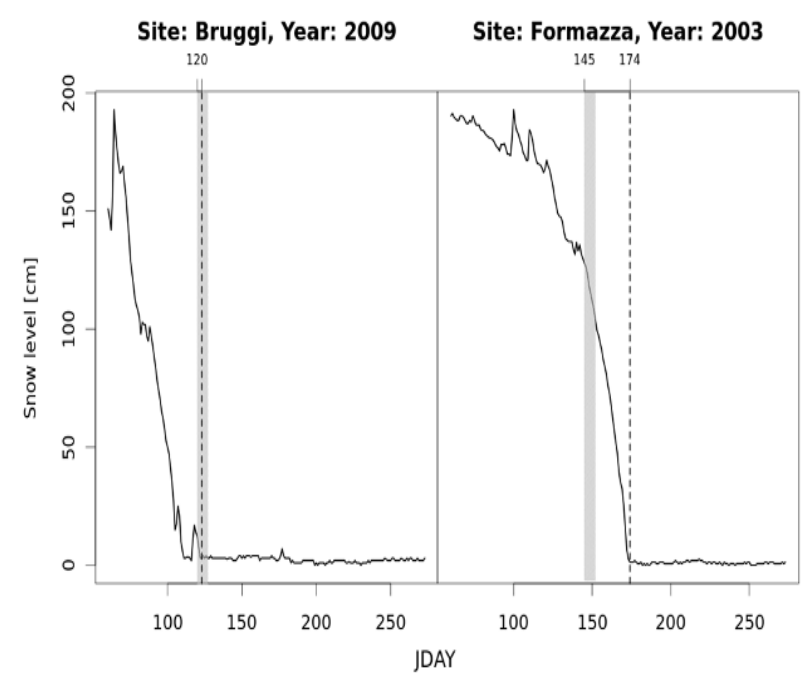

Fig. 7 Time series of the snowmelt period showing snow depth (solid line),

MOD from the snow sensors (dashed line) and from MODIS (the grey polygon denotes the week interval): two examples of good (left) and bad (right) agreement.

A comprehensive analysis of the dataset is shown in Fig. 5, where the calculated difference between snow-sensor derived and MODIS-derived snow-melt dates have been plotted against elevation. The maximum discrepancy (after exclusion of about $4 \%$ data defined as out-layers by the box-plot analysis) was around 30 days.

A simple analysis of the agreement between the two different techniques has shown that for about $38 \%$ of the data, the difference between MODIS-derived and snow-sensor derived MOD were within \pm 10 days, and $70 \%$ within one month.

There is a significant $(\mathrm{p}<0.01)$, although relatively weak $(\mathrm{r}=0.33)$ positive relationship between the calculated delta and the elevation, suggesting that at lower elevation the snowsensor may represent an under-estimation of the spatially integrated snow-cover distribution, while at higher elevations there is a shift from under- to over-estimation. This may be due to the increasing roughness and topographic complexity of the surfaces with increasing altitude. Higher sites may also exhibit stronger snow erosion by wind or other factors, resulting in a spatially-integrated reduction of the snow cover, if compared to snow-sensors that are usually installed in relatively more protected areas.

The non-parametric analysis of variance showed that only two out of nine of the sites displayed an over- or underestimation significantly different from 0 , as shown by the asterisks in Fig. 8. This may lead to conclude that there is a fairly good agreement between MODIS and snow-sensor derived snow melt dates. Additionally, the overall 99\% confidence interval computed on all deltas $(n=88)$ was $-1.6 \pm$ 4.1 days, indicating that the uncertainty level of the comparison falls within the time-frame of MODIS image sampling intervals.
Difference between snow sensor- and Modis-derived snow melt date

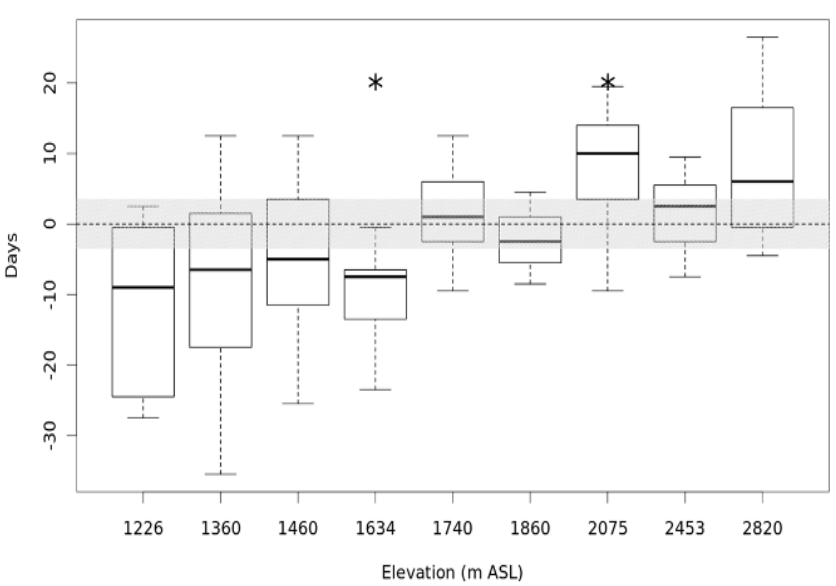

Fig. 8 Box-plots showing the discrepancy between snow-sensor and MODISderived end of snow melt dates, grouped by sites and ordered by increasing altitude. Asterisks denote medians significantly different from 0.

The rough topography and terrain complexity in the mountain regions make it difficult to accurately describe spatial variability of the snow cover. In particular, the snow redistribution plays a key role in determining the amount of snow and the snow melt-out date at a given point, that in turn feedbacks on the biological component of the ecosystem, such as the vegetation composition and the soil development [7], [12]. According to this well acknowledged spatial variability, the agreement between the two independent MOD measurements may be encouraging in further developing this comparison.

\section{CONCLUSIONS}

The two independent automated procedures to derive snow patterns and particularly to define the end of snowmelt have shown a fairly good agreement. Moreover, the study has shown that a strong influence on the relationship between MODIS and snow-sensor derived snow melts may be due to the elevation, with higher sites showing longer lasting snowpacks under the snow sensor than over the 500 m-side grid.

The employment of a programming language has allowed fully exploiting of the dataset, avoiding errors and waste of time.

Moreover, the combination of GIS and VB tools has provided encouraging.

\section{FURTHER DEVELOPMENTS}

The comparison between the two methodologies has shown encouraging results, as previously explained. In order to improve the validation method, further analyses are planned, with the aim of individuating morphological parameters, like slope and aspect [5] or terrain complexity [8], from Digital Elevation Model, of the snow sensor surroundings.

Moreover, stations sites will be characterised, by GIS analyses, defining land use from local or global data (e.g. CORINE) or by in-situ dynamics, as wind and other disturbing 
factors. These data, correlated with validation uncertainties of each sensor will provide additional information in order to define a validation process, and criteria in meteorological station selection.

Validated maps will be employed in several environmental investigation projects, the first one which will exploit these data will concern the modelling of Rock Ptarmigan (Lagopus muta) seasonal cycles

\section{ACKNOWLEDGMENT}

The work has been founded by the EU-INTERREG project "Biodiversità: una ricchezza da conservare"

\section{REFERENCES}

[1] R.G. Barry, R. Armstrong, T. Callaghan, J. Cherry, S. Gearheard, A. Nolin, D. Russell and C. Zöckler, Snow. In Global outlook for ice \& snow. United Nations Environment Programme, Arendal, 2007 pp. 39 62.

[2] Bates, Z. W. Kundzewicz, S. Wu and J. P. Palutikof, "Climate change and water". Technical Paper of the Intergovernmental Pannel on Climate Change. Geneva: IPCC Secretariat. 2008

[3] J. Dozier, "Recent research in snow hydrology". Reviews of Geophysics 25(2), 153-161, 1987.

[4] “ArcGIS Desktop Help: Release 9.2”, Environmental Systems Research Institute, Redlands, CA.

[5] F. Fontana, C. Rixen, T. Jonas, G. Aberegg and S. Wunderle, "Relationship between AVHRR NDVI time series and single point vegetation measurements from an automated climate station network in the Swiss Alps" in Proceedings of the 32nd International Symposium on Remote Sensing of Environment, San José, Costa Rica, 2007

[6] F. Fontana, C. Rixen, T. Jonas, G. Aberegg and S. Wunderle, "Alpine grassland phenology as seen in AVHRR, VEGETATION, and MODIS NDVI time series - a comparison with in situ measurements". Sensors 8, pp. 2833-2853, 2008

[7] M. Freppaz; G. Filippa; A. Caimi; G. Buffa and E. Zanini "Soil and plant characteristics in the alpine tundra (NW Italy)", in B. Gutierrez and C. Pena Eds, Tundras: Vegetation, Wildlife and Climate Trends, Nova Publishers, Hauppauge, NY, pp. 81- 110, 2010.

[8] G. Garnero, "Dalle CTRN ai DB Topografici: verso il riuso delle carte tecniche regionali”, Atti del Convegno Nazionale SIFET 2007, Arezzo, 2007

[9] Gløersen; J. Grimm; A. Hill, C. Lindner; M. Loechl and C. Schürmann, "Mountain areas in Europe: delineation, database and analysis" in Proceedings of the 12th GIS Research UK (GISRUK) Conference, University of East Anglia, Norwich, England. 2004

[10] Godone and G. Garnero, "Modis VBA 2.0” Software, unpublished, 2010

[11] D. K. Hall and G. A. Riggs, "Accuracy assessment of the MODIS snowcover products," Hydrological Processes, 21(12), pp. 1534-1547, 2007

[12] D. K. Hall, G. A. Riggs, V. V. Salomonson, N. E. Di Girolamo and K. A. Bayr, "MODIS snow-cover products", Remote Sensing of Environment, 83, pp. 181-194, 2002

[13] H. Hiller, N. Nuebelt, G. Brollt and F. Holtmeiert, "Snowbedson Silicate Rocksin the Upper Engadine (Central Alps, Switzerland) - Pedogenesis and Interactions among Soil, Vegetation, and Snow Cover”. Arctic, Antarctic, and Alpine Research. 37 (4): 465-476, 2005

[14] Paudel KP and Anderson P, "Monitoring snow cover variability in an agropastoral area in the Trans Himalayan region of Nepal using MODIS data with improved cloud removal methodology". Remote Sensing of Environment 115,2011, pp. 1234-1246

[15] Riggs, G., Hall D.K. and Ackerman S.A., "Sea ice extent and classification with the Moderate Resolution Imaging Spectroradiometer Airborne Simulator (MAS)”, Remote Sensing of Environment, 68(2), 1999, pp. 152-163.

[16] R Development Core Team " $R$ : A language and environment for statistical computing”. R Foundation for Statistical Computing, Vienna, Austria. 2010

[17] S. Singer. and R.W. Popham, "Non-meteorological observations from satellites", Astronautics and Aerospace Engineering, 1(3):89-92, 1963

[18] J. Stroeve, J. E. Box, F. Gao, S. Liang, A. Nolin and C. Schaaf, "Accuracy assessment of the MODIS 16-day albedo product for snow: comparisons with Greenland in situ measurements”, Remote Sensing of Environment, Volume 94, Issue 1, pp 46-60, 2005 